\title{
Correlation between central subfield thickness, visual acuity and structural changes in diabetic macular edema
}

\author{
Correlação entre a espessura do subcampo central, a acuidade visual e mudanças estruturais \\ no edema macular diabético
}

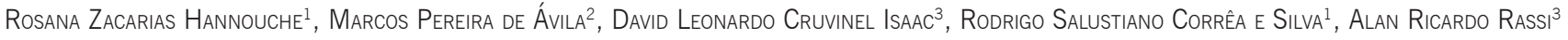

\begin{abstract}
Purpose: To correlate the central subfield thickness (CST) measured by Cirrus ${ }^{\text {TM }}$ SD-OCT with best-corrected visual acuity (BCVA) and structural changes in diabetic macular edema (DME).

Methods: The transversal study evaluated 200 patients with non-proliferative diabetic retinopathy (NPDR) and selected 55 eyes with DME between January, 2010 and April, 2011. Spectral domain OCT was performed in patients with type 2 diabetes and DME. CST and BCVA were correlated with the edema morphology and the ELM (external limiting membrane) integrity. Statistical tests were applied to validate the results.

Results: There was no difference between genders in the NPDR classification. 47.3\% of the patients showed moderate NPDR. The CST average for male was of $393.58 \mu \mathrm{m}$ and $434.16 \mu \mathrm{m}$ for female, with no statistically significant difference. The patients with continuous ELM showed lower CST average $(368.73 \mu \mathrm{m})$ than those with disrupted ELM $(521.43 \mu \mathrm{m})$. There was a strong correlation between the macular volume and CST (59.63\%), but poor correlation between age and CST (2.9\%). Also, there was a significant difference between the average CST and the type of macular edema. Patients with serous detachment showed higher CST average $(488.71 \mu \mathrm{m})$ than those with cystoid macular edema (CME) and diffuse edema. Patients with severe NPDR showed higher CST average ( $491.45 \mu \mathrm{m})$, if compared to mild and moderate NPDR. Cystoid macular edema was the most common type of edema (49.1\%) and showed the worse VA. Patients with disrupted ELM showed worse BCVA. Patients with higher CST showed worse BCVA. There was a significant difference between the CST average of the case group $(407.6 \pm 113,1 \mu \mathrm{m})$ and the control group (diabetic patients without DME: $252 \pm 12.5 \mu \mathrm{m}$ ). There was also a significant difference in the BCVA variables and macular volume between case and control groups.

Conclusion: The study suggests that the CST of diabetic patients with edema is higher than the control group, the increase in CST of diabetic patients with edema leads to worsening of BCVA and macular volume. Continuous ELM showed lower CST average, and the serous detachment showed higher CST average. Cirrus ${ }^{\text {TM }}$ proved to be an important tool in the DME evaluation.
\end{abstract}

Keywords: Diabetic retinopathy; Macular edema; Tomography, optical coherence

\section{RESUMO}

Objetivo: Correlacionar a espessura do subcampo central (ESCC) medida pelo Cirrus ${ }^{T M}$ SD-OCT com a acuidade visual (AV) e as mudanças estruturais no edema macular diabético (EMD).

Métodos: Um estudo transversal avaliou 200 pacientes com retinopatia diabética não proliferativa (RDNP) e selecionados 55 olhos com EMD entre janeiro de 2010 e abril de 2011. OCT spectral foi realizado em pacientes com diabetes tipo 2 e com edema macular diabético (EMD). A ESCC e a AV foram correlacionados com a morfologia do edema e a integridade da membrana limitante externa (MLE). Aplicaram-se testes estatísticos para validação dos resultados.

Resultados: Não houve diferença entre os sexos na classificação RDNP. 47,3\% dos pacientes apresentou RDNP moderada. A média da ESCC no sexo masculino foi de 393,58 um eno feminino de 434,16 $\mu \mathrm{m}$, sem diferença estatística significativa. Pacientes com MLE integra apresentaram menor média da ESCC $(368,73 \mu \mathrm{m})$ que aqueles com MLE descontínua $(521.43 \mu \mathrm{m})$. Encontrou-se forte correlacão entre o volume macular e a ESCC (59,63\%), porém pequena correlação entre a idade e a ESCC (2,9\%). Encontrou-se diferença significativa entre a média da ESCC e o tipo de edema macular, aqueles com descolamento seroso apresentaram maior média de ESCC (488,71 um). Pacientes com RDNP grave apresentaram maior média da ESCC (491,45 $\mu \mathrm{m})$, quando comparados à RDNP leve e moderada. O edema macular cistoide foi o tipo de edema mais frequente $(49,1 \%)$ e apresentou pior AV. Pacientes com MLE integra apresentaram melhor AV. Pacientes com maior ESCC apresentaram pior AV. Houve diferença significativa entre a média da ESCC do grupo de casos (407,60 $1113,05 \mu \mathrm{m})$ e controle (diabéticos sem edema macular: 252,0 $\pm 12,46 \mu \mathrm{m}$ ). Também houve diferença significativa nas variáveis AV e volume macular entre o grupo de casos e controle.

Conclusão: $O$ estudo sugere que a ESCC de diabéticos com edema é maior que o grupo controle; o aumento da ESCC de diabéticos com edema cursa com piora da AV e do volume macular. MLE contínua mostrou menor média da ESCC e o descolamento seroso mostrou maior média da ESCC. Cirrus ${ }^{T M}$ mostrou ser importante ferramenta na avaliação do EMD.

Descritores: Retinopatia diabética; Edema macular; Tomografia de coerência óptica

\section{INTRODUCTION}

Diabetic macular edema (DME) is the leading cause of vision loss in diabetic individuals, although there are different treatments that can delay this impairment ${ }^{(1-3)}$. This complication occurs mainly because of the diabetic retinopathy (DR), a vascular complication of diabetes that frequently is diagnosed and treated later than it should, when the conditions that impair vision already took place. The DR deve- lopment and severity are related to the metabolic control of diabetes. In Brazil, there are about 11.50 million people with diabetes and 5.50 million carry diabetic retinopathy ${ }^{(4)}$.

The most commonly accepted pathophysiological theory for DR is the microvascular dysfunction. Changes in the glucose metabolism lead to alterations in the retinal capillaries and to the hemato-retinal barrier break, resulting in microaneurysms, hemorrhages and exu-
Submitted for publication: November 21, 2011

Accepted for publication: March 25, 2012

Study carried out at Department of Ophthalmology of Reference Center for Ophthalmology (CEROF), Universidade Federal de Goiás - UFG - Goiânia (GO), Brazil.

Physician, Reference Center for Ophthalmology, Universidade Federal de Goiás - UFG - Goiânia (GO), Brazil.

Professor, Department of Ophthalmology, Universidade Federal de Goiás - UFG - Goiânia (GO), Brazil.

${ }^{3}$ Physician, Faculty of Medicine, Universidade Federal de Goiás - UFG - Goiânia (GO), Brazil.
Funding: A doctoral scholarship was given by CAPES to the first author.

Disclosure of potential conflicts of interest: R.Z.Hannouche, None; M.P.Ávila, None; D.L.C.Isaac, None;. R.S.C.Silva None; A.R.Rassi, None.

Correspondence address: Rosana Zacarias Hannouche. Rua 82, número 279, 1101, Setor Sul Goiânia - GO - 74083-010 - Brazil - E-mail: rohannouche@gmail.com

Projeto n: 166/2009. Comitê de Ética em pesquisa humana e animal do Hospital das Clínicas da Universidade Federal de Goiás. 
dates, which in turn lead to detectable retinal thickening in the OCT (Optical Coherence Tomography) ${ }^{(5)}$.

The use of the OCT was incorporated in the work routine of the ophthalmologist after studies demonstrated its collaboration on the detection of the disease. Besides confirming diagnostic impressions, the OCT monitors the pharmacological treatment of the macular edema and follows its progression ${ }^{(6)}$. The introduction of the spectral domain OCT improved the clinical value of the evaluation of eyes with macular diseases, among them the DR. With advanced technology, the Cirrus ${ }^{\mathrm{TM}}$ SD-OCT (spectral domain) acquires data 70 times faster (27.000 versus $400 \mathrm{~A}$-scans per second) and with higher resolution (5 $\mu \mathrm{m}$ versus $10 \mu \mathrm{m}$ of axial resolution in tissue) than previous versions.

DME recognition in the macular exam is able to change the management of the ophthalmologist, combining the diagnosis to the treatment decision, and to be indicative of photocoagulation and/or the use of antiangiogenics ${ }^{(7)}$.

Blumenkranz et al. concluded that many factors influence visual function in eyes with DME, including morphologic pattern of edema (cystic or diffuse retinal thickening), duration of retinal edema, retinal perfusion, total retinal volume, and vitreomacular interface abnormalities (posterior hyaloidal traction, epiretinal membrane, and serous or tractional retinal detachment ${ }^{(8)}$.

Recent findings using Cirrus ${ }^{\mathrm{TM}} \mathrm{SD}-\mathrm{OCT}$ suggest a strong and reliable correlation of photoreceptor outer segment length with visual acuity $^{(9)}$

Otani et al. investigated the correlation of best-corrected visual acuity with foveal microstructural changes of the external limiting membrane and the junction between the inner and outer segments (IS/OS) of the photoreceptors in DME. SD-OCT showed that the integrity of these structures was more strongly correlated with best-corrected visual acuity when compared with central subfield thickness in DME ${ }^{(10)}$.

It is not possible to know if the average photoreceptor outer segment length shortening observed in DME is caused by multiple points of localized breakdown of the IS/OS junction or from generalized thinning of the photoreceptor outer segment. The reasons can be explained based on what is known about the pathophysiology of this disease, such as tissue ischemia, lipid and fluid exudation and accumulation of toxic metabolic waste products and inflammatory mediators in $\mathrm{DME}^{(9)}$. The visual acuity not always is improved after treatments of the macular edema, which suggests that macular thickness is only one of the factors that worsen the visual function. That means that quantitative measurements may not explain all variations in visual acuity, therefore, other factors including macular ischemia and retinal cell function might be important as well.

Maheshwary et al. also considered the disruption of the IS/OS junction an important predictor of visual acuity in DME patients. The integrity of the IS/OS junction can be assessed by SD-OCT and the integrity of retinal architecture is related to final visual acuity. These authors believe that the integrity of the foveal photoreceptor layer is an important predictor of visual acuity. Others factors considered by them as determinative are macular ischemia and accumulated subfoveal hard exudates. These quantitative data by SD-OCT are important to correlate retinal morphology and visual acuity in $\mathrm{DME} \mathrm{E}^{(11)}$. Similar importance was given by Alasil et al. According to them, photoreceptors outer segment thickness is a predictor of function acuity in patients with DME, and the integrity of IS/OS junction is correlated to CST and visual acuity ${ }^{(12)}$.

The study analyzed, using Cirrus ${ }^{\mathrm{TM}}$ SD-OCT, the CST, the edema morphology and the ELM integrity, and correlated them with BCVA in the NPDR.

\section{METHODS}

The transversal work began after approval from the Ethics Committee/Investigational Review Board. The population under study was composed of 200 individuals who agreed to participate in the study by signing an informed consent in accordance with the Term of Free and Informed Consent (IC).

A full ophthalmologic examination was performed. Later on, the fluorescein angiography was performed to classify the cases according to criteria established by the ETDRS for DR and clinically significant macular edema (CSME). Also, CST analyses were performed using the Cirrus ${ }^{\mathrm{TM}}$ SD-OCT device (Zeiss Humphrey Systems, San Leandro, CA). The statistical tests were selected to validate the results and to correlate the findings between OCT and BCVA.

The sample was composed of 55 patients, between January, 2010 and April, 2011, with type 2 diabetes with over 5 years with NPDR and DME, with or without clinical control, aged between the $4^{\text {th }}$ and $7^{\text {th }}$ decade, with any VA and refraction with spherical equivalent between +5.00 and -5.00 diopters, who visited the Reference Center for Ophthalmology in the city of Goiania - GO - Brazil in the established period. Only one eye per patient was considered in the study. The iatrogenic research was performed throughout the study. The control group was composed of 27 patients with type 2 diabetes for less than 5 years, without retinopathy and DME.

Exclusion criteria included macular edema or vascular diseases of other etiologies, laser or prior eye surgery, intravitreal injection, aphakia, opacification of optical media (cataract, corneal edema, leukoma and vitreous hemorrhage), low vision, proliferative diabetic retinopathy, impaired fixation, use of storage drugs, corticosteroids, immunosuppressors and immunomodulators, and intraocular pressure $>21 \mathrm{mmHg}$.

The data was organized according to gender, age, BCVA, the use of Cirrus CST value for an eye according to the ETDRS criteria, the NPDR classification according to criteria adapted from the ETDRS, the macular volume, type of macular edema seen in OCT (diffuse, cystoid macular edema or serous), and external limiting membrane integrity (ELM) (continuous or disrupted). For the investigation of the type of macular edema, it OCT predominant pattern was considered.

The software Microsoft Excel 17.0 was used to store and structure the data for posterior statistical analysis with software SPSS (Statistical Package for Social Sciences). Kruskal-Wallis test was applied to verify the existence of significant statistical difference between visual acuity mean and type of macular edema. T-Student test was applied to correlate the variables gender and ELM integrity; Variance Analysis for CST mean with type of edema and NPDR classification; Mann-Whitney test for visual acuity mean with ELM integrity; Fisher test for gender between case and control groups. Linear Regression was used to correlate CST with variables age, macular volume and visual acuity. It was considered a 95\% confidence level and statistical significance with $p<0.05$.

\section{RESULTS}

There was no significant difference between case and control concerning age. Cases showed higher CST, higher volume and worse BCVA than controls (Table 1) (Linear Regression Analysis).

Most patients in this study showed moderate NPDR (47.3\%), with significant difference of CST among the different NPDR classifications $(p<0.001)$. CST mean values for severe, moderate and mild NPDR were, respectively, $491.4 \mu \mathrm{m}, 364.2 \mu \mathrm{m}$ and $305.1 \mu \mathrm{m}$.

There was a significant difference $(p=0.010)$ between the CST average in relation to the type of edema. $49.1 \%$ of patients showed CME (Table 2) (Variance Analysis).

There were significant differences between the CST in relation to ELM integrity $(p<0.001)$. Patients with disrupted MLE showed higher CST (Table 3) Student's t-test.

There was also a highly significant difference between the NPDR levels in relation to ELM integrity. Patients with disrupted ELM showed worse BCVA. There was a significant difference $(p<0.01)$ between the BCVA mean in relation to ELM integrity (Table 4) (Mann-Whitney test). 
There was a significant difference $(p=0.032)$ between the BCVA mean in comparison with the type of edema (Table 5) (Kruskal-Wallis test).

There was correlation (77\%) between CST and BCVA, and 64\% between volume and BCVA $(p<0.001)$.

Table 1. Parameters of age, CST, BCVA variables and macular volume of control and case groups

\begin{tabular}{lccc}
\hline Variable & Control group & Cases group & p-value \\
\hline Age & $58.92 \pm 9.67$ & $58.76 \pm 8.86$ & 0.942 \\
CST & $252.00 \pm 12.46$ & $407.60 \pm 113.05$ & $<0.001$ \\
BCVA & $0.12 \pm 0.14$ & $0.49 \pm 0.36$ & $<0.001$ \\
Macular volume & $10.10 \pm 0.64$ & $12.96 \pm 3.09$ & $<0.001$ \\
Gender (M/F) & $15 / 12$ & $36 / 19$ & 0.264 \\
\hline
\end{tabular}

$\mathrm{p}=$ statistical significance; $\mathrm{CST}=$ central subfield thickness measured in $\mu \mathrm{m} ; \mathrm{BCVA}=$ visual acuity in logMAR; macular volume measured in $\mathrm{mm}^{3} ; \mathrm{M} / \mathrm{F}=$ male/female

Table 2. CST parameters in relation to the edema morphology. Variance analysis

\begin{tabular}{lccc}
\hline & & \multicolumn{2}{c}{ Parameters } \\
\cline { 3 - 4 } Edema morphology & $\mathbf{N}(\%)$ & CST mean & Standard deviation \\
\hline CME & $27(49.1)$ & 426.7 & 116.7 \\
Serous & $7(12.7)$ & 488.7 & 178.2 \\
Diffuse & $21(38.2)$ & 356.1 & 41.2 \\
\hline
\end{tabular}

$\mathrm{CME}=$ cystoid macular edema; $\mathrm{N}=$ number of cases; $\mathrm{p}=0.010$

Table 3. CST parameters in relation to ELM

\begin{tabular}{lccc}
\hline & & \multicolumn{2}{c}{ Parameters } \\
\cline { 3 - 4 } ELM & N (\%) & CST mean & Standard deviation \\
\hline Continuous & $41(74.5)$ & 368.7 & 64.2 \\
Disrupted & $14(25.5)$ & 521.4 & 147.3 \\
\hline
\end{tabular}

ELM= external limiting membrane; $N=$ number of cases; $C S T=$ central subfield thickness measured in $\mu \mathrm{m} ; \mathrm{p}<0.001$. Student's t-test

Table 4. BCVA parameters in comparison to ELM

\begin{tabular}{lccc}
\hline & & \multicolumn{2}{c}{ Parameters } \\
\cline { 3 - 4 } ELM & N (\%) & BCVA mean & Standard deviation \\
\hline Continuous & $41(74.5)$ & 0.4 & 0.2 \\
Disrupted & $14(25.5)$ & 0.9 & 0.5 \\
\hline
\end{tabular}

$E L M=$ external limiting membrane; $N=$ number of cases; $B C V A=$ visual acuity in logMAR: $\mathrm{p}<0.001$. Mann-Whitney test

Table 5. BCVA parameters in comparison with the macular edema type

\begin{tabular}{lccc}
\hline & & \multicolumn{2}{c}{ Parameters } \\
\cline { 3 - 4 } Edema morphology & N (\%) & BCVA mean & Standard deviation \\
\hline CME & $27(49.1)$ & 0.6 & 0.4 \\
Serous & $7(12.7)$ & 0.5 & 0.6 \\
Diffuse & $21(38.2)$ & 0.4 & 0.2 \\
\hline
\end{tabular}

$\mathrm{CME}=$ cystoid macular edema; $\mathrm{N}=$ number of cases; $\mathrm{BCVA}=$ visual acuity in logMAR; $p<0.032$. Kruskal-Wallis test

\section{DISCUSSION}

Cirrus $^{\text {TM }}$ SD-OCT is one of the high-resolution devices designed for visualizing and measuring in-vivo, through three-dimensional and transversal images, the ocular structures. The device allows visualizing and comparing consecutive exams and existing changes, such as measures of retinal thickness after intra-vitreous injection of antiangiogenic agents. A successful treatment is often anatomically defined as a reduction of intra or subretinal fluids, which results in a reduction of thickness in the ETDRS subfields. Such measures are also important in defining the criteria for inclusion or exclusion in clinical trials, as well as in patient's care, helping on therapeutic decisions and follow-up of the patient's response ${ }^{(13)}$.

Browning et al. suggest the retinal thickness (RT) to be assessed by the CST due to high reproducibility, being based on more scans than the central foveal thickness (CFT), and having higher correlation with other measures of the central macula(14). This statement is corroborated by Alasil et al., who point out that the CFT measure may be more subject to decentralization errors in patients with poor fixation and the CST receives contributions from the parafoveal region, assuming the CST as a better indicator of visual function ${ }^{(12)}$. Han and Jaffe show that changes in RT within the central $1 \mathrm{~mm}$ are more clinically relevant as they relate to changes in the VA, are less susceptible to artifacts and the central thickness measurement can be more reliable than scans performed in peripheral areas ${ }^{(13)}$.

OCT enables to evaluate the edema morphological feature and classifies it in three patterns: cystoid macular edema, serous retinal detachment, and diffuse edema. The segmentation of SD-OCT images identifies each retinal layer, and the damage observed in the foveal ganglionic cell layer can be correlated with the damage in the avascular foveal zone shown in the fluorescein angiography, for example, loss of inner layers of the retina specifically correlates to the capillary non-perfusion and severe ischemia, turning the OCT into a good indicator of ischemic maculopathy ${ }^{(15-17)}$. The correlations between the severity of the outer retinal edema in the OCT and the severity of leakage in the angiography were also described. Simultaneous studies of fluorescein angiography and SD-OCT concluded that the VA is not associated with the presence or absence of cysts ${ }^{(18)}$. However, this study assumes that the VA is a measure of foveal function and then correlates with the number, size, and location of the cysts. In this study, $49.1 \%$ of patients showed CME and, in relation to both BCVA and CST average values, there was a significant difference between the three different patterns of edema.

Murakami et al. associate the pathological changes in the outer retina, especially the ELM and the junction of inner and outer segments of photoreceptors with BCVA. They report in their study that the loss of the ELM, of the junction of outer and inner segments of photoreceptors (OS/IS) and the inner nuclear layer could correspond to the disturbance in the luminous perception by photoreceptors $^{(19)}$.

Park et al. observed the changes in the nerve fiber layer (NFL) of the macula in the early stage of DR using Cirrus ${ }^{\mathrm{TM}}$ SD-OCT. According to the authors, the loss of NFL associated with diabetes occurs before the visible vascular retinopathy and it would be secondary to ischemia caused by retinal vasculopathy, leading to apoptosis of retinal ganglion cells (RGCs). The study observed that the NFL loss occurs mainly in the superior macular region and this could serve to detect early changes in the $\mathrm{DR}^{(20)}$.

As the severity of the retinopathy rises, the retinal thickness increases as well. Browning et al. emphasize that a single initial individualized study for future longitudinal comparisons is important, as the individual variation is wide, with a large standard deviation in the normal population (21). This work has found that the greater the severity of retinopathy, greater is the CST, and the greater the thickness, the greater is macular volume. Browning et al. suggest having a lower threshold to obtain the OCT values as the severity of retinopathy increases. These authors also believe that both clinical 
assessment and the OCT can detect the progression of DME, once the slit lamp evaluation alone can result in errors ${ }^{(21)}$. However, there is no way to predict in which patients the DR will progress. The authors consider that there are no predictive features among the variables usually evaluated by ophthalmologists, which can be safely used in this evaluation. They also suggest a follow-up with interval of 4 to 6 months for these patients, since in patients with subclinical ME the evolution is likely to be slow. Moreover, it is unclear whether patients will return for follow-up appointments.

Blumenkranz et al. and Deák et al. agree that several factors influence on the visual function in eyes with macular edema, such as the edema's morphological characteristics, duration, retinal perfusion, the total retinal volume, and abnormalities in the vitreoretinal interface. Other variables already known as predictors include age, macular leakage on fluorescein angiography and average foveal thickening ${ }^{(8,22)}$. A moderate correlation between RT and VA was suggested in some studies. These authors compared BCVA with RT measurements using Cirrus ${ }^{\mathrm{TM}}$ SD-OCT in a series of 62 eyes of patients with type 2 diabetes. They found only moderate correlation between RT and BCVA in the central fovea (within $500 \mu \mathrm{m}$ ) ${ }^{(23)}$. The present study found a 77\% correlation between BCVA and CST, and a $64 \%$ correlation between BCVA and macular volume.

Recent findings applying Cirrus ${ }^{\mathrm{TM}}$ SD-OCT suggest a strong and reliable correlation between measurements of the outer photoreceptor layer and the $V A^{(9)}$. Otani et al. investigated the changes found in the ELM and in the junction between OS/IS in the diabetic edema and their correlation with the changes in BCVA ${ }^{(10)}$. The SDOCT in this study showed that the integrity of these structures is more related to the BCVA than the CST, as it is more directly related to visual function.

It is unclear if the shortening of the photoreceptors outer segment seen in diabetes is caused by multiple break points of the OS/IS junction, or by a general thinning of the outer photoreceptor layer. The reasons are speculated based on the pathophysiology of the disease, that is, in the tissue ischemia, in the lipid exudation and in the accumulation of inflammatory mediators in the $\mathrm{DME}^{(9)}$. Moreover, the reduction of the macular edema after therapies does not always improve the VA, which suggests that the macular thickness is only one of the several factors that affect the VA. Thus, these measures do not explain all variations in vision, indicating that other factors, such as macular ischemia and function of retinal cells are important as well.

Maheshwary et al. also considered the rupture of the OS/IS junction as an important predictor of VA in patients with DME. The integrity of the retinal photoreceptor layer can be evaluated by the SD-OCT, and this full retinal architecture is correlated with the final $\mathrm{VA}$. The authors believe that the OS/IS integrity is an important predictor factor for VA. Other factors considered by them as VA determinants include macular ischemia and the accumulation of subfoveal hard exudates. These findings were described by these authors for both untreated patients and those treated by pars plana vitrectomy ${ }^{(11)}$. Quantitative data originated from the OCT are important in investigating the relationship between the retinal morphology and visual acuity in the DME. Alasil et al. gave the same consideration to the thickness of the outer photoreceptors layer in his study, which showed to be the thickness of the outer photoreceptors layer the predictor of $\mathrm{VA}^{(12)}$. Our study concluded that the ELM integrity is correlated with the CST. Patients with continuous ELM showed lower CST and significantly better BCVA $(p<0.001)$ than diabetic patients with disrupted ELM. Also, patients with disrupted ELM show higher CST $(p<0.001)$ and worse VA, which supports the idea that the integrity of the retinal layers seen in the OCT holds important clinical implications in the EMD monitoring.

The EMD treatments are more effective in preventing the edema development and vision loss than in restoring both normal macular thickness and lost VA, that is, the early detection is required.
Some studies suggest applying OCT in either eye with DR that will undergo panretinal photocoagulation, once the OCT result may influence the use of adjuvant therapy ${ }^{(21)}$. Virgilli et al. suggest that, in cases of clinical uncertainty about the existence of central EMD, the macular photocoagulation should not be indicated if central retinal thickness is below $250 \mu \mathrm{m}$, while values above $300 \mu \mathrm{m}$ or more are strongly indicative of the need to treatment. Besides, it reinforces the need to not delay the photocoagulation if the thickness is somewhat under $250 \mu \mathrm{m}$, but with a strong clinical suspicion of CSME, especially in patients with non-central CSME ${ }^{(24)}$. However, to base on measurements below $300 \mu \mathrm{m}$ in the OCT, to indicate the treatment of macular edema, is a procedure that can result in treating patients who could improve spontaneously without it. There is a correlation between retinal morphological changes and macular edema, both seen in the OCT, and the visual function loss associated to them, although other factors not yet known interfere with the treatment perspective, which leads to the conclusion that the RT is only one of the indicating factors of the treatment and can be used as an indicator of current therapies. Future studies may identify other factors that act on visual function, such as the electrophysiology. When the OCT is available, it is suggested to relate its data to the clinical evaluation of the slit lamp to avoid possible errors in diagnosis, especially in the initial disease. Still, there may be thinner maculas in patients with mild to moderate DR without edema. Yet, in severe NPDR or PDR, the macula tends to be thicker than in normal eyes, even without clinically detectable thickening.

\section{CONCLUSION}

There were significant differences for variables CST, BCVA and macular volume. A significant correlation was found between retinopathy severity according to NPDR classification and the mean value of CST. The greater the retinopathy severity, the greater the CST and the worse the BCVA. Most of the patients presented moderate NPDR. A strong correlation between volume and CST was found. Patients with serous retinal detachment presented higher mean value of CST, and those with CME presented worse BCVA. Patients with disrupted ELM showed greater mean value of CST and worse BCVA. It was concluded that SD-OCT allows quantitative measurement of CST in the DME and, for identifying the retinal layers individually, also detects retinal structural changes and correlates them to visual functions.

New versions of OCT may be able to be more precise and more sophisticated at defining the usual clinical concepts and doubts relevant to the practical implications of the device. Moreover, data from clinical examination, colorful background photography or fluorescein angiography, combined to OCT, provide a definition with greater predictive power.

Best resolutions, high definition, and refined results with SD-OCT may bring answers with clarity and precision without further definition with the OCT-3 and, along with other diagnostic modalities, explain what is today inconclusive or questionable. The SD-OCT is an excellent replacement of invasive exams to detect and evaluate macular structural changes, and it may, in the near future, explain the functional changes and the visual results of many other retinal diseases. The use of this device in public health campaigns can help to diagnose eyes with macular edema, and be an indicator of early treatment and follow-up on the use of antiangiogenic agents.

\section{AKNOWLEDGMENTS}

The authors would like to thank CAPES for the doctoral scholarship given to the first author.

\section{REFERENCES}

1. Itoi K, Nakamura K, Oku H, Ishizaki E, Sugiyama T, Ueki M, et al. Relationship between diabetic macular edema and peripheral Th1/Th2 balance. Ophthalmologica. 2008; 222(4):249-53. 
2. Grenga P, Lupo S, Domanico D, Vingolo EM. Efficacy of intravitreal triamcinolone acetonide in long standing diabetic macular edema: a microperimetry and optical coherence tomography study. Retina. 2008;28(9):1270-5.

3. Vojusevic S, Benetti E, Massignan F, Pilotto E, Varano M, Cavarzeran F, et al. Screening for diabetic retinopathy: 1 and 3 nonmydriatic 45-degree digital fundus photographs vs 7 standard early treatment diabetic retinopathy study fields. Am J Ophthalmol. 2009;148(1):111-8

4. Taleb A, Ávila MP, Moreira H. As condições de saúde ocular no Brasil: 2008. São Paulo: Walprint Gráfica e Editora.

5. Hannouche RZ. Medida da espessura retiniana no edema macular diabético clinicamente significativo, pela tomografia de coerência óptica [Dissertação]. Goiânia: Universidade Federal de Goiás; 2009.

6. Browning DJ, Fraser CM. The predictive value of patient and eye characteristics on the course of subclinical diabetic macular edema. Am J Ophthalmol. 2008;145(1):149-54

7. Mitchell P, Bandello F, Schmidt-Erfurth U, Lang GE, Massin P, Schlingemann RO, Sutter F, Simader C, Burian G, Gerstner O, Weichselberger A; RESTORE study group. The RESTORE study: ranibizumab monotherapy or combined with laser versus laser monotherapy for diabetic macular edema. Ophthalmology. 2011;118(4):615-25.

8. Blumenkranz MS, Haller JA, Kuppermann BD, Williams GA, Ip M, Davis $M$, et al Correlation of visual acuity and macular thickness measured by optical coherence tomography in patients with persistent macular edema. Retina. 2010;30970:1090-4 Comment in Retina. 2011;31(4):815; author reply 815-6.

9. Forooghian F, Stetson PF, Meyer SA, Chew EY, Wong WT, Cukras C, et al. Relationship between photoreceptor outer segment length and visual acuity in diabetic macular edema. Retina. 2010;30(1):63-70.

10. Otani T, Yamaguchi Y, Kishi S. Correlation between visual acuity and foveal microstructural changes in diabetic macular edema. Retina. 2010;30(5):774-80.

11. Maheshwary AS, Oster SF, Yuson RM, Cheng L, Mojana F, Freeman WR. The association between percent disruption of the photoreceptor inner segment-outer segment junction and visual acuity in diabetic macular edema. Am J Ophthalmol. 2010;150(1):63-7.e1.

12. Alasil T, Keane PA, Updike JF, Dustin L, Ouyang Y, Walsh AC, et al. Relationship between optical coherence tomography retinal parameters and visual acuity in diabetic macular edema. Ophthalmology. 2010;117(12):2379-86.

13. Han IC, Jaffe GJ. Evaluation of artifacts associated with macular spectral-domain optical coherence tomography. Ophthalmology. 2010;117(6):1177-89.e4.
14. Browning DJ, Apte RS, Bressler SB, Chalam KV, Danis RP, Davis MD, Kollman C, Qin $\mathrm{H}$, Sadda S, Scott IU; Diabetic Retinopathy Clinical Research Network. Association of the extent of diabetic macular edema as assessed by optical coherence tomography with visual acuity and retinal outcome variables. Retina. 2009;29(3):300-5.

15. Loduca AL, Zhang $C$, Zelkha $R$, Shahidi $M$. Thickness mapping of retinal layers by spectral-domain optical coherence tomography. Am J Ophthalmol. 2010;150(6):849-55.

16. Byeon SH, Chu YK, Lee H, Lee SY, Kwon OW. Foveal ganglion cell layer damage in ischemic diabetic maculopathy: correlation of optical coherence tomographic and anatomic changes. Ophthalmology. 2009;116(10):1949-58.e8.

17. Yeung L, Lima VC, Garcia P, Landa G, Rosen RB. Correlation between spectral domain optical coherence tomography findings and fluorescein angiography patterns in diabetic macular edema. Ophthalmology. 2009;116(6):1158-67.

18. Brar M, Yuson R, Kozak I, Mojana F, Cheng L, Bartsch DU, et al. Correlation between morphologic features on spectral-domain optical coherence tomography and angiographic leakage patterns in macular edema. Retina. 2010;30(3):383-9.

19. Murakami T, Nishijima K, Sakamoto A, Ota M, Horii T, Yoshimura N. Association of pathomorphology, photoreceptor status, and retinal thickness with visual acuity in diabetic retinopathy. Am J Ophthalmol. 2011:151(2):310-7.

20. Park HY, Kim IT, Park CK. Early diabetic changes in the nerve fiber layer at the macula detected by spectral domain optical coherence tomography. $\mathrm{Br} J$ Ophthalmol. 2011;95(9):1223-8.

21. Browning DJ, Fraser CM, Clark S. The relationship of macular thickness to clinically graded diabetic retinopathy severity in eyes without clinically detected diabetic macular edema. Ophthalmology. 2007;115(3):533-9.e2

22. Deák GG, Bolz M, Ritter M, Prager S, Benesch T, Schmidt-Erfurth U; Diabetic Retinopathy Research Group Vienna. A systematic correlation between morphology and functional alterations in diabetic macular edema. Invest Ophthalmol Vis Sci. 2010; 51(12):6710-4.

23. Nunes S, Pereira I, Santos A, Bernardes R, Cunha-Vaz J. Central retinal thickness measured with HD-OCT shows a weak correlation with visual acuity in eyes with CSME. Br J Ophthalmol. 2011;94(9):1201-4.

24. Virgilli G, Menchini F, Dimastrogiovanni AF, Rapizzi E, Menchini U, Bandello F, et al. Optical coherence tomography versus stereoscopic fundus photography or biomicroscopy for diagnosing diabetic macular edema: a systematic review. Invest Ophthalmol Vis Sci. 2007:48(11):4963-73.

\title{
Simpósio de Retina 20/20 do \\ Simpósio de Retina 20/20 do Banco de Olhos de Sorocaba
}

\author{
25 a 27 de outubro de 2012 \\ Banco de Olhos de Sorocaba \\ Sorocaba (SP)
}

Informações:

Tel.: (15) 3212-7077

E-mail: sinbos@bos.org.br 